\title{
DESEMPENHO DO ARROZ DE TERRAS ALTAS COM A APLICAÇÃO DE DOSES DE NITROGÊNIO E EM SUCESSÃO ÀS CULTURAS DE COBERTURA DO SOLO EM SISTEMA DE PLANTIO DIRETO $\left({ }^{1}\right)$
}

\author{
DISNEI AMÉLIO CAZETTA $\left({ }^{2}\right)$; ORIVALDO ARF $\left({ }^{3}\right)$; SALATIER BUZETTI $\left({ }^{3}\right)$; \\ MARCO EUSTÁQUIO DE SÁ( $\left({ }^{3}\right)$; RICARDO ANTÔNIO FERREIRA RODRIGUES( $\left.{ }^{3}\right)$
}

\begin{abstract}
RESUMO
A área cultivada no sistema de plantio direto no Brasil tem sido incrementada rapidamente e a cultura do arroz de terras altas pode ser incluída no sistema, em rotação com outras culturas. Outro aspecto importante é a utilização de adubação adequada sendo o nitrogênio um dos nutrientes absorvidos em maior quantidade pelo arroz. Assim, o objetivo do trabalho foi o de avaliar algumas características agronômicas e a produtividade do arroz de terras altas, cv. IAC 202, utilizando-se a combinação de culturas de cobertura - milheto, sorgo granífero, milho, guandu, crotalária, mucuna-preta, além da vegetação espontânea no pousio e doses de $\mathrm{N}$ em cobertura - zero, 25, 50, 75, 100 e $125 \mathrm{~kg} \mathrm{ha}^{-1}$, no município de Selvíria (MS), nos anos agrícolas 2001/2002 e 2002/2003. Considerando-se os resultados, concluiu-se que a cultura do sorgo é opção viável ao fornecimento de adequada quantidade de massa de matéria seca e ao recobrimento da superfície do solo, mas não para o aumento da produtividade na cultura do arroz em sucessão, em sistema de plantio direto em terras altas; a situação é inversa com a cultura do guandu como planta de cobertura, sendo a produtividade na cultura do arroz em sucessão, em sistema de plantio direto em terras altas, distintamente influenciada pela adubação nitrogenada, em dois anos consecutivos.
\end{abstract}

Palavras-chave: Oryza sativa L., culturas de cobertura, irrigação por aspersão, N em cobertura.

\section{ABSTRACT \\ PERFORMANCE OF UPLAND RICE TO THE NITROGEN RATES AFTER DIFFERENT COVER CROPS IN NO-TILL SYSTEM}

The area cropped in no till system has increased very fast and upland rice can be included in rotation system with other crops. Another important aspect is the adequate fertilization and nitrogen is one of nutrients uptake in higher quantity by rice. Thus, this study aimed to evaluate the performance of upland rice, IAC 202 cultivar, through combination of covering crops pearl (millet, grain sorghum, corn, pigeonpea, sun hemp, velvet bean and fallow) and sidedressing nitrogen (zero, 25, 50, 75, 100, and $125 \mathrm{~kg} \mathrm{ha}^{-1}$ ) in Selvíria county, Mato Grosso do Sul State, Brazil, in 2001/2002 and 2002/2003 growth years. The grain sorghum is a good option to provide high dry mass and recovery the soil surface but no for increasing productivity of rice in succession in no till system; the situation is inverse to pigeon pea used as cover crop; the rice productivity, in succession, in no-till system on upland is influenced differently by nitrogen fertilization, in two followed years.

Key words: Oryza sativa L., cover crops, sprinkler irrigation, sidedressing nitrogen.

$\left({ }^{1}\right)$ Parte do trabalho de Graduação do primeiro autor. Projeto financiado pela FAPESP. Recebido para publicação em 23 de agosto de 2006 e aceito em 18 de outubro de 2007.

$\left({ }^{2}\right)$ Doutorando, Departamento de Produção Vegetal - Universidade Estadual Paulista - UNESP, Campus de Jaboticabal, Via de acesso Prof. Paulo Donato Castellane, s/n, 14884-900 Jaboticabal (SP), Brasil. E-mail: disnei@fcav.unesp.br. (*) Autor correspondente.

$\left({ }^{3}\right)$ Departamento de Fitotecnia, Economia e Sociologia Rural, Universidade Estadual Paulista (UNESP), Campus de Ilha Solteira, Caixa Postal 31, 15385-000, Ilha Solteira (SP), Brasil. E-mail: arf@agr.feis.unesp.br; sbuzetti@agr.feis.unesp.br; mesa@agr.feis.unesp.br; ricardo@agr.feis.unesp.br 


\section{INTRODUÇÃO}

Apesar das inovações tecnológicas nas décadas dos anos 80 e 90, há muitos desafios na pesquisa agronômica brasileira no que se refere à cultura do arroz de terras altas e a obtenção de soluções para os problemas da cultura é ponto de destaque desta pesquisa no Brasil. O maior desafio é a consolidação da cultura, de forma sustentável, como um componente dos sistemas de produção de grãos, especialmente no sistema de plantio direto (SPD). O sucesso desse sistema de cultivo é dependente da rotação de culturas e, principalmente, da produção de palhada, sendo um reservatório de nutrientes liberados paulatinamente pela ação dos microrganismos, e contribuindo para o aumento da estabilidade estrutural e proteção do solo contra a erosão hídrica (KeMPER e DERPSCH, 1981; Sidiras et al., 1982, citados por FRANCHINI et al., 2000).

Segundo Fageria (1983), a capacidade intrínseca de produção agrícola dos solos está íntima e diretamente relacionada aos seus teores de matéria orgânica e de N; por outro lado, é difícil manter-se um nível satisfatório desses dois componentes na maioria dos solos cultivados. Assim, os métodos de adição e de manutenção de matéria orgânica devem ser considerados com antecipação, em todos os programas de manejo dos solos cultivados. Bordin et al. (2003), trabalhando com coberturas vegetais semeadas na safrinha (outono-inverno), antes da sucessão de cultivos feijão de inverno-arroz, obtiveram produção de massa de matéria seca (MMS) de 6.275 $\mathrm{kg} \mathrm{ha}^{-1}$ com feijão bravo do Ceará (Canavalia brasiliensis); $6.854 \mathrm{~kg} \mathrm{ha}^{-1}$ com crotalária (Crotalaria juncea); $9.579 \mathrm{~kg} \mathrm{ha}^{-1}$ com milheto (Pennisetum glaucum); $12.686 \mathrm{~kg} \mathrm{ha}^{-1}$ com sorgo AG-2501C (Sorghum bicolor) e $12.814 \mathrm{~kg} \mathrm{ha}^{-1}$ com sorgo guiné (Sorghum bicolor tipo guinea), com cortes realizados aos 70 dias após a semeadura. Também observaram, nas gramíneas produtoras de fitomassa, elevada extração de nutrientes, principalmente de $\mathrm{K}, \mathrm{P}, \mathrm{Mg}$ e $\mathrm{S}$, demonstrando que, com sua utilização como plantas de cobertura, têm atuação na reciclagem de nutrientes que, muitas vezes, estão indisponíveis às culturas anuais em vista de sua localização nos horizontes sub-superficiais no solo. As leguminosas, por meio da fixação biológica de $\mathrm{N}_{2}$ atmosférico, proporciona fornecimento posterior de $\mathrm{N}$ às culturas agrícolas. TEIXEIRA et al. (2005) observaram, no milheto em cultivo solteiro, elevados teores de macronutrientes como K, P, Mg e S por ocasião do manejo dessa cultura de cobertura. CARVAlHo (2000), trabalhando com culturas de cobertura antecedendo a safra de verão, verificou produção de MMS da ordem de $10.000 \mathrm{~kg}$ $\mathrm{ha}^{-1}$ com o milheto e de $5.000 \mathrm{~kg} \mathrm{ha}^{-1}$ com crotalária, com cortes realizados aos 70 dias após a semeadura.
Cazetta et al. (2005), também trabalhando com culturas de cobertura de crotalária e milheto antes da safra de verão, obtiveram valores de $5.267 \mathrm{~kg} \mathrm{ha}^{-1}$ para a primeira e $10.673 \mathrm{~kg} \mathrm{ha}^{-1}$ para a segunda espécie, em cortes aos 60 dias após a semeadura; verificaram ainda que, com milheto, reciclam-se quantidades apreciáveis de nutrientes pela mineralização da MMS produzida, com destaque para o nitrogênio. Verificase, assim, a importância do cultivo de coberturas vegetais em áreas onde se utiliza o SPD.

A recomendação atual da adubação nitrogenada para o arroz de terras altas no SPD é 40 a $90 \mathrm{~kg} \mathrm{ha}^{-1} \mathrm{de}$ $\mathrm{N}$, dependendo da suscetibilidade da cultivar ao acamamento e ao brusone (FAGERIA, 1998). O suprimento de $\mathrm{N}$ às plantas no SPD, comparativamente ao convencional, deve ser superior em razão da maior perda de nitrato pela lixiviação, menor decomposição dos restos culturais, mais volatilização de amônia e mais imobilização microbiana (SALET et al., 1997). A introdução de matéria orgânica com alta relação $\mathrm{C} / \mathrm{N}$ é determinante do aumento da imobilização microbiana do $\mathrm{N}$ e de sua menor disponibilidade inicial às plantas (RIZZARDI, 1995); demonstra-se, assim, a importância da rotação de culturas com a alternância de gramíneas e leguminosas para minimizar o efeito da imobilização microbiana bem como da aplicação de N. O efeito da adubação nitrogenada na cultura do arroz é variável, ora com incremento de produtividade (FARINELLI et al., 2004; Bordin et al., 2003 e STONE et al., 1999), ora sem (ArF et al., 1996; ArF et al., 2003).

Ressalta-se a importância do estudo no SPD e das coberturas vegetais nas alterações das propriedades químicas e físicas do solo e da adubação nitrogenada, evidenciando-se a necessidade de se aplicarem os conhecimentos sobre essas práticas no cultivo do arroz, visando à obtenção de produtividades maiores.

\section{MATERIAL E MÉTODOS}

O trabalho foi realizado nos anos agrícolas de 2001/2002 e 2002/2003, em área experimental localizada no município de Selvíria (MS), situada a $51^{\circ} 22^{\prime}$ de longitude Oeste e $20^{\circ} 22^{\prime}$ de latitude Sul, na altitude de 335 metros, em solo da região de cerrado tipo Latossolo Vermelho Distrófico típico argiloso (EMBRAPA, 1999). O clima da região, segundo a classificação de Köppen, é Aw. A temperatura média anual é de $23,5^{\circ} \mathrm{C}$, a média nos meses mais quentes, janeiro e fevereiro, é de $25,7^{\circ} \mathrm{C}$ e nos mais frios, junho e julho, $20,6{ }^{\circ} \mathrm{C}$. Os valores médios anuais de precipitação pluvial e de umidade relativa do ar são, respectivamente, de $1.370 \mathrm{~mm}$ e $75 \%$. Os dados climáticos observados durante o período de desenvolvimento do experimento, nas duas safras, estão ilustrados nas figuras $1 \mathrm{a}$ e $1 \mathrm{~b}$. 

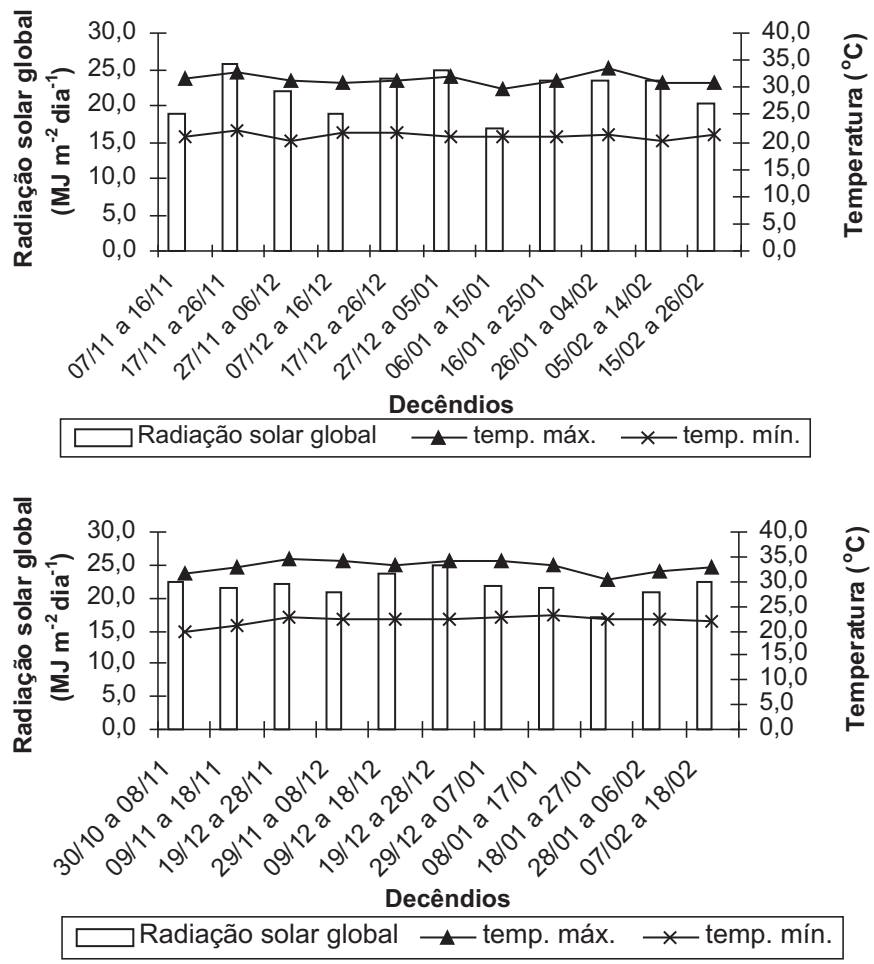

Figura 1. Dados climáticos por decêndios em Selvíria (MS), safras 2001/2002 (a) e 2002/2003 (b), no período dos experimentos.

Antes da instalação dos experimentos foram coletadas amostras de solo deformadas da área experimental e realizada a análise química de acordo com método proposto por RaIj e QuagGio (1983), obtendo-se os seguintes resultados: $\mathrm{pH}\left(\mathrm{CaCl}_{2}\right)=5,5$; M.O. $=28 \mathrm{~g} \mathrm{dm}^{-3} ; \mathrm{P}($ resina $)=25 \mathrm{mg} \mathrm{dm}^{-3} ; 2,1 ; 30 ; 17$; 28; 77, $1 \mathrm{mmol}_{\mathrm{c}} \mathrm{dm}^{-3}$ de $\mathrm{K}, \mathrm{Ca}, \mathrm{Mg}, \mathrm{H}+\mathrm{Al} \mathrm{e} \mathrm{CTC}$, respectivamente, e $64 \%$ de saturação por bases.

$\mathrm{O}$ experimento foi instalado em local onde o sistema plantio direto estava sendo utilizado havia mais de três anos. O fornecimento de água, quando necessário, foi realizado por meio de um sistema fixo de irrigação por aspersão, sendo os dados climatológicos e aqueles auxiliares à irrigação obtidos na Estação Meteorológica da Fazenda de Ensino e Pesquisa da FEIS-UNESP, situada em Selvíria (MS.

Na segunda semana de agosto de 2001 e de 2002, após a colheita do feijão de inverno, foram semeados na área experimental: milheto cv. BN-2 (Pennisetum glaucum), sorgo granífero AGN 8050 (Sorghum bicolor), milho AGN 3050 (Zea mays), guandu (Cajanus cajan), crotalária (Crotalaria juncea), mucunapreta (Mucuna aterrima) e mantida uma área em pousio, com vegetação espontânea (capim-colchão Digitaria sp, capim-carrapicho - Cenchrus echinatus e capim-marmelada - Brachiaria plantaginea), sendo irrigados por aspersão, objetivando-se o desenvolvimento de diferentes coberturas vegetais para implantação do arroz em plantio direto, em novembro de 2001 e de 2002. As culturas utilizadas como coberturas vegetais não foram adubadas, sendo o manejo realizado de acordo com as práticas culturais recomendadas para cada uma delas. Na segunda quinzena de outubro de 2001 e 2002, aos 60 dias após a semeadura, a área foi manejada com TRITON (triturador de fitomassa), para corte, desintegração e distribuição uniforme dos restos vegetais. Após alguns dias foi realizada a dessecação da área com o herbicida gliphosate (1.560 $\mathrm{g} \mathrm{ha}^{-1}$ do i.a).

$\mathrm{O}$ delineamento experimental utilizado foi o de blocos casualizados, dispostos em esquema fatorial $7 \times 6$, constituído pela combinação das sete culturas de cobertura e seis doses de nitrogênio em cobertura - zero, 25, 50, 75, 100 e $125 \mathrm{~kg} \mathrm{ha}^{-1}$ para o arroz, com quatro repetições. As parcelas foram constituídas por nove linhas de arroz com seis metros de comprimento e espaçadas $0,34 \mathrm{~m}$ entre si, sendo considerada como úteis as três linhas centrais, desprezando-se $0,5 \mathrm{~m}$ nas extremidades.

A semeadura do arroz foi realizada mecanicamente, em 7 de novembro de 2001 e 30 de outubro de 2002, utilizando-se a cultivar IAC 202. Utilizou-se um número de sementes necessário para se obterem 120 plantas $\mathrm{m}^{-2}$ e realizado o tratamento de sementes com thiodicarb + óxido de zinco $(600+$ $500 \mathrm{~g}$ do i.a. por $100 \mathrm{~kg}$ de sementes), visando-se principalmente ao controle de cupins (Synterms molestus, Procorniterms striatus e Cornitermes leslesii) e de lagarta elasmo (Elasmopalpus lignosellus).

Como na área de cultivo tem ocorrido com mais freqüência capim-colchão (Digitaria $s p$ ), capimcarrapicho (Cenchrus echinatus) e capim-marmelada (Brachiaria plantaginea), como vegetação espontânea, foi aplicado, logo após a semeadura, o herbicida préemergente oxadiazon (1.000 $\mathrm{g} \mathrm{ha}^{-1}$ do i.a.). Para as plantas daninhas não controladas pelo herbicida, foi utilizada a capina manual. A adubação básica do arroz constituiu-se de $250 \mathrm{~kg} \mathrm{ha}^{-1}$ da formulação 4$30-10+0,4 \%$ de $\mathrm{Zn}$, calculada de acordo com as características químicas do solo e considerando-se a produtividade esperada de $4.000 \mathrm{~kg} \mathrm{ha}^{-1}$ (CANTARELLA et al., 1996). A adubação de cobertura com diferentes doses de $\mathrm{N}$ foi realizada aos 30 dias após a emergência das plântulas, no "ponto de algodão", utilizando-se como fonte à uréia seguida de irrigação, para diminuição da volatilização da amônia.

A colheita do arroz foi efetuada manualmente quando, em $50 \%$ das panículas, os grãos dos $2 / 3$ superiores estavam duros e os do terço inferior, semiduros. 
Após a colheita, foi realizada a trilha mecânica e secagem à sombra em bandejas com jornal até que os grãos estivessem com $13 \%$ de umidade. Posteriormente, foi realizada a limpeza do material, separando-se a palha e os grãos chochos com auxílio de uma peneira, por meio de abanação manual.

As avaliações realizadas durante o desenvolvimento do trabalho foram:

a) massa de matéria seca (MMS) das coberturas vegetais - determinada após a passagem do desintegrador mecânico, coletando-se os restos vegetais, utilizando-se um quadrado de $0,5 \mathrm{~m}$ de lado e área de $0,25 \mathrm{~m}^{2}$, em dois pontos por parcela; essas amostras foram acondicionadas em sacos de papel, devidamente identificadas e levadas para o laboratório para secagem em estufa de ventilação forçada à temperatura de $60-70{ }^{\circ} \mathrm{C}$ até ponto de equilíbrio constante, fazendo-se a quantificação e extrapolando em $\mathrm{kg} \mathrm{ha}^{-1}$.

b) cobertura morta do solo - determinada aos 20 dias após a emergência do arroz, pelo método do Ponto Quadrado proposto por SPEDDING e LARGE (1957).

c) teor de $\mathbf{N}$ nas folhas: por ocasião do florescimento, coletou-se o limbo foliar de 30 folhas bandeira por parcela e, após secagem, foram desintegradas em moinho tipo Wiley, e submetidas à digestão sulfúrica, conforme método descrito em SARRUge e HaAg (1974).

d) altura de plantas: distância média compreendida, em metros desde a superfície do solo até a extremidade superior da panícula mais alta, determinada durante o estádio de grãos na forma pastosa, em 10 plantas ao acaso, na área útil de cada parcela.

e) grau de acamamento: obtido em observações visuais na fase de maturação, utilizandose a seguinte escala de notas: 0 - sem acamamento; 1 - até $5 \%$ de plantas acamadas; 2 - 5 a 25\%, 3 - 25 a $50 \% ; 4-50$ a $75 \%$ e $5-75$ a $100 \%$ de plantas acamadas.

f) número de colmos e de panículas: determinado pela contagem do número de colmos e panículas em 1,0m de fileira de plantas, expressandose os valores por metro quadrado.

g) número de espiguetas cheias por panícula: determinado pela contagem do número de espiguetas granadas em 15 panículas por parcela, logo após separação das chochas, por fluxo de ar.

h) espiguetas estéreis por panícula (\%): obtido pela contagem do número de espiguetas totais e chochas em 15 panículas por parcela, logo após separação das cheias e chochas, utilizando-se fluxo de ar; em seguida, fez-se a divisão das chochas pelo total de espiguetas.

i) massa de cem grãos: avaliada pela pesagem de duas amostras de cem grãos em cada parcela, com $13 \%$ base úmida.

j) produtividade de grãos: determinada pela pesagem dos grãos em casca, provenientes da área útil da parcela, corrigindo-se a umidade para $13 \%$ e convertendo-se o valor em $\mathrm{kg} \mathrm{ha}^{-1}$.

As análises estatísticas foram realizadas pelo programa estatístico SANEST (MACHADO e ZONTA, 1991), utilizando-se o teste de Tukey a 5\% de probabilidade, para comparação entre as médias. Realizou-se a análise de regressão polinomial para as características avaliadas em relação às doses crescentes de adubação nitrogenada em cobertura.

\section{RESULTADOS E DISCUSSÃO}

Para as diferentes culturas de cobertura utilizadas anteriormente à cultura do arroz (Tabela 1), foram constatados em média, valores de MMS acima de $6.000 \mathrm{~kg} \mathrm{ha}^{-1}$, nas duas safras, com exceção das áreas com guandu e em pousio, não avaliadas na safra 2001/2002, com valores inferiores a $3.000 \mathrm{~kg}^{-} \mathrm{ha}^{-}$ ${ }^{1}$. BORDIN et al. (2003) obtiveram valores semelhantes para crotalária - $6.854 \mathrm{~kg} \mathrm{ha}^{-1}$, e superiores para milheto - $9.579 \mathrm{~kg} \mathrm{ha}^{-1}$ e sorgo - $12.814 \mathrm{~kg} \mathrm{ha}^{-1}$, em cortes aos 70 dias após a semeadura. CARVALHO (2000) obteve valores superiores para o milheto aproximadamente $10.000 \mathrm{~kg} \mathrm{ha}^{-1} \mathrm{e}$ inferiores para crotalária - aproximadamente $5.000 \mathrm{~kg} \mathrm{ha}^{-1}$, também realizando cortes aos 70 dias após a semeadura. CAZETTA et al. (2005), obtiveram valores de $10.673 \mathrm{~kg}$ $\mathrm{ha}^{-1}$ e de $5.267 \mathrm{~kg} \mathrm{ha}^{-1}$, respectivamente para essas mesmas espécies, em cortes aos 60 dias após a semeadura. Os dados referentes à cobertura do solo pelas culturas antecedentes, avaliados aos 20 dias após a emergência do arroz, nas duas safras, estão apresentados na Tabela 1. Verifica-se que, nas áreas com cultivos anteriores de sorgo, milheto, milho, mucuna-preta e de crotalária, nas duas safras o recobrimento foi superior a $50 \%$, o que deve ter possibilitado mais proteção inicial do solo contra a erosão hídrica, redução nas amplitudes térmicas e menores taxas de evaporação de água, sendo possivelmente favorecido o desenvolvimento da cultura do arroz em sucessão.

A altura de plantas (Tabela 2) não foi influenciada pelas culturas de cobertura antecessoras à cultura do arroz na safra 2001/2002. Já na safra 2002/2003, no arroz após cultivo anterior do sorgo a altura foi menor; a maior altura foi proporcionada 
onde houve o cultivo anterior de guandu. Quanto às doses de nitrogênio, os dados foram ajustados a equação linear crescente, em ambas as safras. Segundo MARSCHNer (1995), em cereais, com a aplicação de doses elevadas de $\mathrm{N}$ antes do ponto de crescimento transformar-se em estrutura reprodutiva, aumenta-se à produção de fitormônios, especialmente de auxinas, estimulantes aos processos de divisão e de expansão celular, aumentando-se o elongamento do caule e, conseqüentemente, a altura das plantas; por outro lado, com a luz em alta intensidade ou quantidade poderão ser oxidadas e inativadas as auxinas. Entretanto, com o incremento na altura não foi ocasionado acamamento das plantas, em ambos os anos de cultivo, evidenciando-se, assim, a resistência da cultivar em estudo.

Tabela 1. Valores médios de massa de matéria seca de coberturas vegetais e porcentagem de cobertura morta do solo, aos 20 dias após a emergência do arroz IAC 202. Selvíria (MS), 2001/2002 e 2002/2003

\begin{tabular}{|c|c|c|c|c|}
\hline \multirow{2}{*}{ Tratamentos } & \multicolumn{2}{|c|}{ Produção de massa de matéria seca } & \multicolumn{2}{|c|}{ Cobertura do solo } \\
\hline & $2001 / 2002$ & $2002 / 2003$ & $2001 / 2002$ & $2002 / 2003$ \\
\hline Culturas de cobertura & 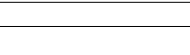 & & 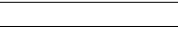 & \\
\hline Sorgo $\left({ }^{1}\right)$ & 9384 a & 7609 a & $68 \mathrm{a}$ & $78 \mathrm{a}$ \\
\hline Milheto $\left({ }^{2}\right)$ & $7282 \mathrm{ab}$ & 6017 a & 77 a & $62 \mathrm{ab}$ \\
\hline Milho $\left({ }^{3}\right)$ & $8025 \mathrm{ab}$ & 8159 a & $74 \mathrm{a}$ & $57 \mathrm{ab}$ \\
\hline M. preta $\left({ }^{4}\right)$ & $6250 \mathrm{~b}$ & $6651 \mathrm{a}$ & 59 a & 76 a \\
\hline Guandu $\left({ }^{5}\right)$ & 2697 c & $2992 \mathrm{~b}$ & $34 \mathrm{~b}$ & $12 \mathrm{c}$ \\
\hline Crotalária $\left({ }^{6}\right)$ & $6023 \mathrm{~b}$ & 6316 a & $67 \mathrm{a}$ & $49 \mathrm{~b}$ \\
\hline Pousio & - & $1962 \mathrm{~b}$ & $15 \mathrm{~b}$ & $25 \mathrm{c}$ \\
\hline Teste F & $15,07^{* *}$ & $22,48^{* *}$ & $21,93^{* *}$ & $28,82^{* *}$ \\
\hline DMS (Tukey 5\%) & 2699 & 2288 & 22,6 & 21,49 \\
\hline $\mathrm{CV}(\%)$ & 17,8 & 17,3 & 17,6 & 17,9 \\
\hline
\end{tabular}

** = significativo a $1 \%$ de probabilidade pelo teste $\mathrm{F}$.

Médias seguidas por letras iguais na mesma coluna não são diferentes entre si a 5\% de probabilidade pelo teste de Tukey.

$\left({ }^{1}\right)$ Sorghum bicolor; $\left({ }^{2}\right)$ Pennisetum glaucum; $\left({ }^{3}\right)$ Zea mays; $\left({ }^{4}\right)$ Mucuna aterrima; $\left({ }^{5}\right)$ Cajanus cajan;

$\left({ }^{6}\right)$ Crotalaria juncea.

Quanto ao número de colmos $\mathrm{m}^{-2}$ (Tabela 2), verificaram-se, nos tratamentos com cultivo anterior de sorgo e milheto os menores valores nas duas safras, sem diferenças significativas entre aqueles das demais culturas de cobertura. Já, com a adubação nitrogenada em cobertura, houve influência positiva no número de colmos $\mathrm{m}^{-2}$, na safra 2001/2002, e ajuste dos dados à equação linear crescente, similarmente ao obtido por CAMPELlo Junior (1985); o mesmo não se verificou na safra 2002/2003. Em relação ao número de panículas por metro quadrado (Tabela 2), foram obtidos no tratamento com cultivo anterior com sorgo os menores valores nas duas safras; já a adubação nitrogenada em cobertura, teve-se influência positiva no número de panículas $\mathrm{m}^{-2}$ na safra 2001/2002, de forma linear crescente. Constatou-se o papel importante do nitrogênio no desenvolvimento dos perfilhos produtivos até a máxima dose utilizada - $125 \mathrm{~kg} \mathrm{ha}^{-1}$ de $\mathrm{N}$, considerando-se que a aplicação foi realizada aos 30 dias após a emergência das plantas; o mesmo não foi verificado na safra $2002 / 2003$. SтоNE et al. (1999), trabalhando com doses entre 0 e $160 \mathrm{~kg} \mathrm{ha}^{-1}$ de $\mathrm{N}$, obtiveram resposta quadrática para o número de panículas por metro quadrado, com valor máximo na dose de 130,8 $\mathrm{kg} \mathrm{ha}^{-1}$ de N. CAMPello Junior (1985) e Bordin et al (2003) também constataram aumento no número de panículas por área com a adubação nitrogenada, utilizando como fonte a uréia. Já ARF et al. (2003), não verificaram influência da adubação nitrogenada em cobertura no número de panículas por área, utilizando como fonte a uréia.

Os teores de $\mathrm{N}$ na folha bandeira (Tabela 3) não foram influenciados pelas culturas anteriores ao arroz. Entretanto, todas as doses de adubação nitrogenada utilizadas estiveram na faixa considerada adequada - 27 a $35 \mathrm{~g} \mathrm{~kg}^{-1}$ (CANTARella et al., 1996); houve, porém, aumento linear com a elevação da dose de $\mathrm{N}$ aplicada, em ambas as safras. Esse resultado foi decorrente do aumento da disponibilidade de $\mathrm{N}$, suficiente para elevação da concentração do elemento no tecido vegetal. O número de espiguetas cheias foi influenciado pela cobertura vegetal na safra 2001/2002; na área anteriormente ocupada com mucuna-preta obteve-se o menor valor, o mesmo não ocorrendo na safra 2002/2003 (Tabela 3). 
Tabela 2. Valores médios de altura de plantas e do número de colmos e de panículas em arroz IAC 202, cultivado após diferentes culturas de cobertura e aplicação de nitrogênio em cobertura. Selvíria (MS), 2001/2002 e 2002/2003

\begin{tabular}{|c|c|c|c|c|c|c|}
\hline \multirow{2}{*}{ Tratamentos } & \multicolumn{2}{|c|}{ Altura de plantas } & \multicolumn{2}{|c|}{ Colmos } & \multicolumn{2}{|c|}{ Panículas } \\
\hline & $2001 / 2002$ & $2002 / 2003$ & $2001 / 2002$ & $2002 / 2003$ & $2001 / 2002$ & $2002 / 2003$ \\
\hline Culturas de cobertura & \multicolumn{2}{|c|}{$\mathrm{m}$} & \multicolumn{4}{|c|}{ número $\mathrm{m}^{-2}$} \\
\hline Sorgo $\left({ }^{1}\right)$ & $0,92 \mathrm{a}$ & $0,93 \mathrm{c}$ & $221 \mathrm{~b}$ & $190 \mathrm{c}$ & $140 \mathrm{~b}$ & $142 \mathrm{~b}$ \\
\hline Milheto $\left({ }^{2}\right)$ & 0,98 a & $0,96 \mathrm{bc}$ & $259 \mathrm{ab}$ & $193 \mathrm{bc}$ & $187 \mathrm{a}$ & $157 \mathrm{ab}$ \\
\hline Milho $\left({ }^{3}\right)$ & $0,97 \mathrm{a}$ & $0,98 \mathrm{ab}$ & 268 a & $217 \mathrm{abc}$ & $188 \mathrm{a}$ & $176 \mathrm{ab}$ \\
\hline M. preta $\left({ }^{4}\right)$ & 0,93 a & $0,95 \mathrm{bc}$ & $277 \mathrm{a}$ & $232 \mathrm{ab}$ & $202 \mathrm{a}$ & $179 \mathrm{ab}$ \\
\hline Guandu $\left({ }^{5}\right)$ & 0,98 a & $1,01 \mathrm{a}$ & $271 \mathrm{a}$ & 239 a & 207 a & $185 \mathrm{a}$ \\
\hline Crotalária $\left({ }^{6}\right)$ & $0,97 \mathrm{a}$ & $0,98 \mathrm{ab}$ & $291 \mathrm{a}$ & $229 \mathrm{abc}$ & 217 a & 183 a \\
\hline Pousio & 0,97 a & $0,98 \mathrm{ab}$ & 291 a & $224 \mathrm{abc}$ & $200 \mathrm{a}$ & $170 \mathrm{ab}$ \\
\hline Teste F - C. de cobertura $(C)$ & $2,24^{*}$ & $5,67^{* *}$ & $5,68^{* *}$ & $3,89^{* *}$ & $9,35^{* *}$ & $3,18^{* *}$ \\
\hline DMS (Tukey 5\%) & 7,26 & 4,35 & 42,71 & 40,99 & 34,58 & 37,20 \\
\hline \multicolumn{7}{|l|}{ Doses de N (kg ha-1) } \\
\hline 0 & $0,93\left(^{1}\right)$ & $0,95\left(^{2}\right)$ & $245\left({ }^{3}\right)$ & 204 & $178^{(4)}$ & 162 \\
\hline 25 & 0,94 & 0,96 & 254 & 210 & 183 & 166 \\
\hline 50 & 0,95 & 0,97 & 264 & 232 & 189 & 186 \\
\hline 75 & 0,97 & 0,98 & 273 & 214 & 194 & 174 \\
\hline 100 & 0,98 & 0,98 & 282 & 224 & 200 & 170 \\
\hline 125 & 0,99 & 0,99 & 291 & 221 & 205 & 165 \\
\hline Teste F - Doses de N (D) & $2,37^{*}$ & $3,15^{*}$ & $3,68^{* *}$ & $1,30^{\text {n.s. }}$ & $2,00^{\text {n.s. }}$ & $1,17^{\text {n.s. }}$ \\
\hline Teste F (Reg. Linear) & $11,37^{* *}$ & 12,60 ** & $16,78^{* *}$ & $2,12^{\text {n.s. }}$ & $9,15^{* *}$ & $0,048^{\text {n.s. }}$ \\
\hline Teste F (Reg. Quadrática) & $0,17^{\text {n.s. }}$ & $0,39^{\text {n.s. }}$ & $1,19^{\text {n.s. }}$ & $1,23^{\text {n.s. }}$ & $0,011^{\text {n.s. }}$ & $3,66^{\text {n.s. }}$ \\
\hline Teste F (Interação C x D) & $0,56^{\text {n.s. }}$ & $0,86^{\text {n.s. }}$ & $1,42^{\text {n.s. }}$ & $0,62^{\text {n.s }}$ & $1,06^{\text {n.s. }}$ & $0,89^{\text {n.s. }}$ \\
\hline CV $(\%)$ & 8,7 & 5,2 & 18,4 & 21,8 & 20,9 & 25,3 \\
\hline
\end{tabular}

$\left({ }^{1}\right) \mathrm{y}=92,9464+0,0511 \mathrm{x}$

$\left({ }^{2}\right) \mathrm{y}=95,0833+0,0322 \mathrm{x}$

$\left({ }^{3}\right) \mathrm{y}=245,3163+0,3655 \mathrm{x}$

$\left({ }^{4}\right) \mathrm{y}=177,9642+0,2186 \mathrm{x}$

n.s. = não significativo; ${ }^{*} \mathrm{e}^{* *}=$ significativo a $5 \%$ e $1 \%$ de probabilidade pelo teste $\mathrm{F}$ respectivamente

Médias seguidas por letras iguais na mesma coluna não são diferentes entre si a $5 \%$ de probabilidade pelo teste de Tukey.

$\left({ }^{1}\right)$ Sorghum bicolor; $\left({ }^{2}\right)$ Pennisetum glaucum; $\left({ }^{3}\right)$ Zea mays; $\left({ }^{4}\right)$ Mucuna aterrima; $\left({ }^{5}\right)$ Cajanus cajan; $\left({ }^{6}\right)$ Crotalaria juncea.

Bordin et al. (2003), trabalhando com algumas culturas de coberturas, verificaram que, com o feijãobravo-do-Ceará obteve-se o maior número de espiguetas cheias por panícula, seguindo-se a crotalária e milheto. Já, com o $\mathrm{N}$ em cobertura foi proporcionada redução linear no número de espiguetas cheias por panícula na safra 2001/2002, o mesmo não ocorrendo na safra 2002/2003, como apresentado na Tabela 3; demonstra-se assim, o efeito de elementos climáticos como temperatura e radiação solar no florescimento e enchimento dos grãos (Figuras 1a e 1b). BoRDIN et al. (2003) verificaram aumento no número de espiguetas cheias por panícula com o aumento das doses de N. FARINELLI et al. (2004) e Arf et al. (2003), utilizando como fonte de $\mathrm{N}$ a uréia, não observaram influência da adubação nitrogenada nesse parâmetro. Em relação ao número de espiguetas estéreis, verificaram-se maiores valores no tratamento com cultivo anterior de sorgo, e os menores naqueles com a mucuna-preta e crotalária na safra 2001/2002, não se observando influência das coberturas vegetais na safra 2002/03.

Com a adubação nitrogenada em cobertura não se proporcionaram diferenças no número de espiguetas estéreis por panícula nas duas safras (Tabela 3), corroborando resultados obtidos por FARINELLI et al. (2004) e ARF et al. (2003), sendo, porém, discordantes dos de Bordin et al. (2003), que verificaram maior porcentagem de espiguetas estéreis na maior dose utilizada - $75 \mathrm{~kg} \mathrm{ha}^{-1} \mathrm{de} \mathrm{N}$, com o IAC 202. 
Tabela 3. Valores médios de $\mathrm{N}$ na folha bandeira, número de espiguetas totais, cheias e chochas por panícula em arroz IAC 202, cultivado após diferentes coberturas vegetais e aplicação de nitrogênio em cobertura. Selvíria (MS), $2001 / 02$ e $2002 / 03$

\begin{tabular}{|c|c|c|c|c|c|c|}
\hline \multirow[t]{2}{*}{ Tratamentos } & \multicolumn{2}{|c|}{ Teor de $\mathrm{N}$} & \multicolumn{2}{|c|}{$\begin{array}{l}\text { Espiguetas cheias } \\
\text { por panícula }\end{array}$} & \multicolumn{2}{|c|}{$\begin{array}{c}\text { Espiguetas estéreis } \\
\text { por panícula }\end{array}$} \\
\hline & $2001 / 2002$ & $2002 / 2003$ & $2001 / 2002$ & $2002 / 2003$ & $2001 / 2003$ & $2002 / 2003$ \\
\hline Culturas de cobertura & \multicolumn{2}{|c|}{$\mathrm{g} \mathrm{kg}^{-1}$} & \multicolumn{2}{|c|}{ número } & \multicolumn{2}{|c|}{$\%$} \\
\hline Sorgo $\left({ }^{1}\right)$ & $29,2 \mathrm{a}$ & 30,31 a & $171 \mathrm{ab}$ & $215 \mathrm{a}$ & $16,2 \mathrm{a}$ & $14,2 \mathrm{a}$ \\
\hline Milheto $\left({ }^{2}\right)$ & $29,3 \mathrm{a}$ & 30,56 a & 188 a & $216 a$ & $12,4 \mathrm{~b}$ & $14,0 \mathrm{a}$ \\
\hline Milho $\left({ }^{3}\right)$ & $29,3 \mathrm{a}$ & 30,87 a & $178 \mathrm{ab}$ & $210 \mathrm{a}$ & $13,1 \mathrm{ab}$ & $13,9 \mathrm{a}$ \\
\hline M. preta $\left({ }^{4}\right)$ & $28,8 \mathrm{a}$ & $31,53 \mathrm{a}$ & $160 \mathrm{~b}$ & 193 a & $12,5 \mathrm{~b}$ & $14,7 \mathrm{a}$ \\
\hline Guandu $\left({ }^{5}\right)$ & 29,6 a & 30,83 a & 188 a & $209 a$ & $12,5 \mathrm{~b}$ & $13,0 \mathrm{a}$ \\
\hline Crotalária $\left({ }^{6}\right)$ & $29,9 \mathrm{a}$ & 31,47 a & $168 \mathrm{ab}$ & $197 \mathrm{a}$ & $12,6 \mathrm{~b}$ & $14,1 \mathrm{a}$ \\
\hline Pousio & $28,9 \mathrm{a}$ & $31,02 \mathrm{a}$ & 193 a & $203 \mathrm{a}$ & $11,5 \mathrm{~b}$ & $14,7 \mathrm{a}$ \\
\hline Teste F - C. de -cobertura (C) & 0,52 n.s & 1,15 n.s & $3,55^{* *}$ & $2,25 *$ & $3,61 * *$ & 1,15 n.s. \\
\hline DMS (Tukey 5\%) & 1,45 & 1,76 & 27,62 & 24,62 & 3,31 & 2,24 \\
\hline \multicolumn{7}{|l|}{ Doses de N (kg ha-1) } \\
\hline 0 & $28,1\left({ }^{1}\right)$ & $30,11\left(^{2}\right)$ & $186\left({ }^{3}\right)$ & 205 & 13,2 & 14,5 \\
\hline 25 & 28,6 & 30,44 & 183 & 207 & 12,7 & 14,4 \\
\hline 50 & 29,1 & 30,77 & 179 & 209 & 11,9 & 14,2 \\
\hline 75 & 29,6 & 31,11 & 176 & 193 & 12,2 & 14,4 \\
\hline 100 & 30,0 & 31,44 & 173 & 210 & 13,5 & 13,4 \\
\hline 125 & 30,5 & 31,77 & 170 & 212 & 14,4 & 13,6 \\
\hline Teste F - Doses N (D) & $2,75^{*}$ & $2,98^{*}$ & $1,55^{\text {n.s. }}$ & $1,62^{\text {n.s. }}$ & $1,61^{\text {n.s. }}$ & $0,92^{\text {n.s. }}$ \\
\hline Teste F (Reg. Linear) & $12,73^{* *}$ & $13,11^{* *}$ & $4,78^{*}$ & $0,50^{\text {n.s. }}$ & $0,06^{\text {n.s. }}$ & $2,26^{\text {n.s. }}$ \\
\hline Teste F (Reg. Quadrática) & $0,03^{\text {n.s. }}$ & $0,61^{\text {n.s. }}$ & $0,40^{\text {n.s. }}$ & $1,61^{\text {n.s. }}$ & $3,65^{\text {n.s. }}$ & $0,20^{\text {n.s. }}$ \\
\hline Teste F (Interação (C x D & $0,54^{\text {n.s }}$ & $0,83^{\text {n.s }}$ & $0,94^{\text {n.s. }}$ & $0,84^{\text {n.s. }}$ & $0,85^{\text {n.s. }}$ & $0,74^{\text {n.s. }}$ \\
\hline C.V. $(\%)$ & 10,0 & 6,6 & 17,9 & 13,8 & 29,5 & 18,4 \\
\hline
\end{tabular}

(1) $\mathrm{Y}=28,1418+0,0189 \mathrm{x}$

$\left({ }^{2}\right) \mathrm{Y}=30,1057+0,0133 \mathrm{x}$

$\left({ }^{3}\right) \mathrm{Y}=185,8013-0,1261 \mathrm{x}$

n.s. = não significativo; ${ }^{*} \mathrm{e}^{* *}=$ significativo a $5 \%$ e $1 \%$ de probabilidade pelo teste $\mathrm{F}$ respectivamente.

Médias seguidas por letras iguais na mesma coluna não são diferentes entre si a 5\% de probabilidade pelo teste de Tukey.

$\left({ }^{1}\right)$ Sorghum bicolor; $\left({ }^{2}\right)$ Pennisetum glaucum; $\left({ }^{3}\right)$ Zea mays; $\left({ }^{4}\right)$ Mucuna aterrima; $\left({ }^{5}\right)$ Cajanus cajan; $\left({ }^{6}\right)$ Crotalaria juncea.

A massa de 100 grãos não foi influenciada pelas coberturas vegetais utilizadas anteriormente ao arroz nas duas safras (Tabela 4); já Bordin et al. (2003) verificaram superioridade do milheto e da crotalária para essa característica, entre as coberturas vegetais. Com a aplicação de nitrogênio em cobertura, também não foi influenciado esse componente produtivo, em concordância com resultados de ARF et al. (2003); STONE et al. (1999), utilizando como fonte de $\mathrm{N}$ o sulfato de amônio; FARINELLI et al. (2004) e em discordância dos obtidos por Bordin et al. (2003); AQUiNo (1984), utilizando a uréia. Tal avaliação é dependente da cultivar, da época de aplicação do $\mathrm{N}$, do nível de água disponível e da produtividade de grãos.
Com relação à produtividade de grãos, com a cobertura vegetal de sorgo anteriormente ao cultivo do arroz, na safra $2001 / 02$, foi proporcionada a menor produtividade de grãos; na safra 2002/2003, só foi menor e estatisticamente diferente de grandu e crotalária (Tabela 4) e, em campo, menor altura de plantas de arroz. Bordin et al. (2003) também verificaram diminuição da produtividade do arroz após o sorgo utilizado como cobertura vegetal. O efeito da adubação nitrogenada em cobertura foi linear crescente na produtividade de grãos, na safra 2001/ 2002, e com o aporte de $125 \mathrm{~kg} \mathrm{ha}^{-1}$ de $\mathrm{N}$, em cobertura, foi acarretado incremento de $20,2 \%$ na produtividade de grãos em relação à do tratamento testemunha; o mesmo não ocorreu na safra 2002/2003. 
Bordin et al. (2003), trabalhando com doses de $\mathrm{N}$ em cobertura, no sistema plantio direto, verificaram a maior produtividade do arroz IAC $202 \mathrm{com}$ a dose de $50 \mathrm{~kg} \mathrm{ha}^{-1}$ de N. Para FArinell et al. (2004), a dose foi de $75 \mathrm{~kg} \mathrm{ha}^{-1}$, no sistema plantio direto. StONe et al. (1999), trabalhando com adubação nitrogenada em arroz, com irrigação suplementar por aspersão verificaram, para produtividade, uma resposta quadrática ao N, com o máximo de $5.523 \mathrm{~kg} \mathrm{ha}^{-1} \mathrm{com}$ $112,9 \mathrm{~kg} \mathrm{ha}^{-1}$ de N. ARF et al. $(1996 ; 2003)$ não constataram influência da adubação nitrogenada em cobertura na produtividade do arroz, utilizando como fonte de $\mathrm{N}$ a uréia. Tais diferenças podem ser decorrentes das cultivares utilizadas, clima, solo, época de aplicação e dose de $\mathrm{N}$, dentre outros.

Interessante ressaltar o efeito negativo do sorgo na produtividade do arroz, mesmo com produção de quantidade adequada de palhada, podendo atribuir esse comportamento ao efeito aleloquímico que o sorgo possui. Roth et al. (2000) verificaram que, devido aos compostos alelopáticos presentes no resíduo do sorgo, a produtividade do trigo é reduzida entre $10 \%$ e $25 \%$. Quando o resíduo do sorgo é incorporado, após sua colheita, ocorre atraso na emergência do trigo, mas não se tem efeito alelopático positivo na produtividade de grãos, pois há rápida degradação dos compostos alelopáticos do sorgo. Já no plantio direto dos cultivares de trigo sobre o resíduo de sorgo, a emergência não é afetada, porém há redução na produtividade de grãos, provavelmente pela lenta degradação dos compostos alelopáticos do sorgo. Observa-se que a incorporação do resíduo do sorgo para redução dos efeitos alelopáticos no trigo pode não ser compatível com a conservação do solo para se prevenir erosão.

Tabela 4. Valores médios da massa de 100 grãos e produtividade de grãos em arroz IAC 202, cultivado após diferentes coberturas vegetais e aplicação de nitrogênio em cobertura. Selvíria (MS), 2001/2002 e 2002/2003

\begin{tabular}{|c|c|c|c|c|}
\hline \multirow{2}{*}{ Tratamentos } & \multicolumn{2}{|c|}{ Massa de 100 grãos } & \multicolumn{2}{|c|}{ Produtividade de grãos } \\
\hline & $2001 / 2002$ & $2002 / 2003$ & $2001 / 2002$ & $2002 / 2003$ \\
\hline Culturas de cobertura & +2 & +2 & +2 & + \\
\hline Sorgo $\left({ }^{1}\right)$ & $2,40 \mathrm{a}$ & $2,30 \mathrm{a}$ & $2257 \mathrm{~b}$ & $3112 \mathrm{c}$ \\
\hline Milheto $\left({ }^{2}\right)$ & $2,39 \mathrm{a}$ & $2,38 \mathrm{a}$ & $3639 a$ & 3501 bc \\
\hline Milho $\left({ }^{3}\right)$ & $2,43 \mathrm{a}$ & $2,36 \mathrm{a}$ & 3150 a & $3629 \mathrm{abc}$ \\
\hline M. preta $\left({ }^{4}\right)$ & $2,33 \mathrm{a}$ & $2,29 \mathrm{a}$ & 3327 a & $3384 \mathrm{bc}$ \\
\hline Guandu $\left({ }^{5}\right)$ & $2,32 \mathrm{a}$ & $2,34 \mathrm{a}$ & 3675 a & 4131 a \\
\hline Crotalária $\left({ }^{6}\right)$ & $2,28 \mathrm{a}$ & $2,32 \mathrm{a}$ & $3761 \mathrm{a}$ & $3847 \mathrm{ab}$ \\
\hline Pousio & $2,39 \mathrm{a}$ & $2,33 \mathrm{a}$ & 3331 a & $3633 \mathrm{abc}$ \\
\hline Teste F-C. de cobertura (C) & $1,31^{\text {n.s. }}$ & $1,57^{\text {n.s. }}$ & $7,20^{* *}$ & $5,68^{* *}$ \\
\hline DMS (Tukey a 5\%) & 0,19 & 0,11 & 810,55 & 580,56 \\
\hline \multicolumn{5}{|l|}{ Doses de N $\left(\mathrm{kg} \mathrm{ha}^{-1}\right)$} \\
\hline 0 & 2,39 & 2,35 & $3003^{(1)}$ & 3438 \\
\hline 25 & 2,31 & 2,33 & 3124 & 3720 \\
\hline 50 & 2,37 & 2,34 & 3245 & 3584 \\
\hline 75 & 2,39 & 2,33 & 3366 & 3614 \\
\hline 100 & 2,39 & 2,30 & 3488 & 3747 \\
\hline 125 & 2,32 & 2,33 & 3609 & 3528 \\
\hline Teste F - Doses N (D) & $0,80^{\text {n.s. }}$ & $0.41^{\text {n.s. }}$ & $2,07^{\text {n.s. }}$ & $0,84^{\text {n.s. }}$ \\
\hline Teste F (Reg. Linear) & $0,082^{\text {n.s. }}$ & $0,65^{\text {n.s. }}$ & $8,18^{* *}$ & $0,28^{\text {n.s. }}$ \\
\hline Teste F (Reg. Quadrática) & $0,21^{\text {n.s. }}$ & $0,14^{\text {n.s. }}$ & $0,65^{\text {n.s. }}$ & $1,51^{\text {n.s. }}$ \\
\hline Teste F (Interação C x D) & $0,80^{\text {n.s. }}$ & $0,52^{\text {n.s. }}$ & $0,95^{\text {n.s. }}$ & $1,15^{\text {n.s. }}$ \\
\hline C.V. $(\%)$ & 9,4 & 5,6 & 28,3 & 18,6 \\
\hline
\end{tabular}

$\left({ }^{1}\right) \mathrm{y}=3003,3860+4,8422 \mathrm{x}$

n.s. $=$ não significativo; ${ }^{*} \mathrm{e}^{* *}=$ significativo a $5 \%$ e $1 \%$ de probabilidade pelo teste $\mathrm{F}$ respectivamente.

Médias seguidas por letras iguais na mesma coluna não são diferentes entre si a $5 \%$ de probabilidade pelo teste de Tukey.

$\left({ }^{1}\right)$ Sorghum bicolor; $\left({ }^{2}\right)$ Pennisetum glaucum; $\left({ }^{3}\right)$ Zea mays; $\left({ }^{4}\right)$ Mucuna aterrima; $\left({ }^{5}\right)$ Cajanus cajan; $\left({ }^{6}\right)$ Crotalaria juncea. 


\section{CONCLUSÕES}

1. A cultura do sorgo é opção viável ao fornecimento de adequada quantidade de massa de matéria seca e ao recobrimento da superfície do solo, mas não para o aumento da produtividade na cultura do arroz em sucessão, em sistema de plantio direto em terras altas; a situação é inversa com a cultura do guandu como planta de cobertura;

2. A produtividade na cultura do arroz em sucessão, em sistema de plantio direto em terras altas, é distintamente influenciada pela adubação nitrogenada, em dois anos consecutivos.

\section{REFERÊNCIAS}

AQUINO, A.R.L. Níveis de aplicação de uréia ${ }^{15} \mathbf{N}$ no arroz (Oriza sativa L.) submetidos a veranicos. Piracicaba, 1984. 134p. Tese ( Doutorado em Solos e Nutrição de Plantas) - Escola Superior de Agricultura "Luiz de Queiroz", Universidade de São Paulo.

ARF, O.; RODRIGUES, R.A.F.; CRUSCIOL, C.A.C.; SÁ, M.E.; BUZETTI, S. Manejo do solo e adubação nitrogenada para cultivares de arroz de terras altas irrigadas por aspersão. Scientia Agrícola, Piracicaba, v.60, n.2, p.348-352, 2003.

ARF, O.; SÁ, M. E.; RODRIGUES, R. A. F.; BUZZETI, S.; STRADIOTO, M. F.; PASTANA, A. R. M. P. Comportamento de cultivares de arroz para condição de sequeiro irrigado por aspersão em diferentes doses de adubação nitrogenada em cobertura. Científica, Jaboticabal, v.24, n.1, p.85-97, 1996.

BORDIN, L.; FARINELLI, R.; PENARIOL, F.G.; FORNASIERI FILHO, D. Sucessão de cultivo de feijão-arroz com doses de adubação nitrogenada após adubação verde, wm semeadura direta. Bragantia, Campinas, v.62, n.3, p.417-428, 2003.

CAMPELLO JUNIOR, J.O. Avaliação da capacidade de extração de água do solo pelo arroz de sequeiro (Oryza sativa L.) sob diferentes doses de nitrogênio. Piracicaba, 1985. 127p. Tese (Doutorado em Solos e Nutrição de Plantas) - Escola Superior de Agricultura "Luiz de Queiroz", Universidade de São Paulo.

CANTARELLA, H.; RAIJ, B. van.; CAMARGO, C.E.O. Cereais. In: RAIJ, V. van.; CANTARELLA, H.; QUAGGIO,J.A.;FURLANI, A.M.C. Recomendações de calagem e adubação para o Estado de São Paulo. 2.ed. Campinas: Instituto Agronômico/Fundação IAC. 1996, p.43-73. (Boletim Técnico, 100)

CARVALHO, M.A.C. Adubação verde e sucessão de culturas em semeadura direta e convencional em Selvíria-MS. 2000. 189f. (Tese Doutorado) - Faculdade de Ciências Agrárias e Veterinárias, Universidade Estadual Paulista, Jaboticabal.

CAZETTA, D. A. C.; FORNASIERI FILHO, D.; GIROTTO, F. Composição, produção de matéria seca e cobertura do solo em cultivo exclusivo e consorciado de milheto e crotalária. Acta Scientiarum Agronomy, Maringá, v.27, n.4, p.575-580, 2005.

EMPRESA BRASILEIRA DE PESQUISA AGROPECUÁRIA. Sistema Brasileiro de Classificação dos solos. Rio de Janeiro: EMBRAPA/CNPSO, 1999. 412p.
FAGERIA, N. K. Manejo químico do solo. In: Cultura do arroz de sequeiro: fatores afetando a produtividade. Piracicaba: Instituto da Potassa e do Fosfato - Instituto Internacional da Potassa, 1983. p.239-260.

FAGERIA, N. K. Manejo da calagem e da adubação do arroz. In: BRESEGUELLO, F.; STONE, L. F. (Ed.). Tecnologia para o arroz de terras altas. Santo Antônio de Goiás: Embrapa Arroz e Feijão, 1998. p.67-78.

FARINELLI, R.; PENARIOL, F. G.; FORNASIERI FILHO, D.; BORDIN, L. Características agronômicas de arroz de terras altas sob plantio direto e adubação nitrogenada e potássica. Revista Brasileira de Ciência do Solo, Viçosa, v.28, n.3, p.447-454, 2004.

FRANCHINI, J. C.; BORKERT, C. M.; FERREIRA, M. M.; GUADÊNCIO, C. A. Alterações na fertilidade do solo em sistema de rotação de culturas em semeadura direta. Revista Brasileira de Ciência do Solo, Viçosa, v.24, n.2, p.459-467, 2000.

MACHADO, A.A.; ZONTA, E.P. Manual do Sanest: Sistema de análise estatística para microcomputadores. Pelotas: UFPel, 1991. 102 p.

MARSCHNER, H. Mineral nutrition of higher plants. 2.ed. San Diego, Academic Press, 1995. 889p.

RAIJ, B. van; QUAGGIO, J.A. Métodos de análise de solo para fins de fertilidade. Campinas: Instituto Agronômico, 1983. 31p. (Boletim técnico, B1).

RIZZARDI, M. A. Manejo de nitrogênio no sistema plantio direto. In: SEMINÁRIO INTERNACIONAL DO SISTEMA PLANTIO DIRETO, 1., 1995, Passo Fundo, RS. Resumos expandidos... Passo Fundo: EMBRAPA-CNPT, 1995. p.95-99.

ROTH, C. M.; SHROYER, J. P.; PAULSEN, G.M. Allelopathy of sorghum on wheat under several tillage systems, Agronomy Journal, v.92, n.5, p.855-860, 2000.

SALET, R. L.; VARGAS, L. K.; ANGHINONI, I.; KOCHHANN, R. A.; DENARDIN, J. E.; CONTE, E. Porque a disponibilidade de nitrogênio é menor no sistema plantio direto? In: SEMINÁRIO INTERNACIONAL DO SISTEMA PLANTIO DIRETO, 2., 1997, Passo Fundo, RS. Anais... Passo Fundo: EMBRAPA-CNPT, 1997. p.217-219.

SARRUGE, J.R.; HAAG, H.P. Análises químicas em plantas. Piracicaba: ESALQ, 1974. 56p. (mimeografado)

SPEDDING, C.R.W.; LARGE, R.V. A point-quadrat method for the description of pasture in terms of height and density. Grass and forage science, Oxford, v.12, n.4, p.229-234, 1957.

STONE, L. F.; SILVEIRA, P. M.; MOREIRA, J. A. A.; YOKOYAMA, L. P. Adubação nitrogenada em arroz sob irrigação suplementar por aspersão. Pesquisa Agropecuária Brasileira, Brasília, v.34, n.6, p.927-932, 1999.

TEIXEIRA, C. M.; CARVALHO, G. J.; FURTINI NETO, A. E.; ANDRADE, M. J. B.; MARQUES, E. L. S. Produção de biomassa e teor de macronutrientes do milheto, feijão-de-porco e quandu-anão em cultivo solteiro e consorciado. Ciência e Agrotecnologia, Lavras, v.29, n.1, p.93-99, 2005. 